Bidirectional longitudinal relationship between leisure-time physical activity and psychotropic medication usage : A register linked follow-up study

\title{
Stubbs, Brendon
}

2017-01

Stubbs , B , Vancampfort , D , Mänty , M , Svärd , A , Rahkonen , O \& Lahti , J 2017 , '

Bidirectional longitudinal relationship between leisure-time physical activity and psychotropic medication usage : A register linked follow-up study ', Psychiatry Research, vol. 247 , pp. 208-213 . https://doi.org/10.1016/j.psychres.2016.11.033

http://hdl.handle.net/10138/233266

https://doi.org/10.1016/j.psychres.2016.11.033

publishedVersion

Downloaded from Helda, University of Helsinki institutional repository.

This is an electronic reprint of the original article.

This reprint may differ from the original in pagination and typographic detail.

Please cite the original version. 


\title{
Bidirectional longitudinal relationship between leisure-time physical activity and psychotropic medication usage: A register linked follow-up study
}

\author{
Brendon Stubbs ${ }^{\mathrm{a}, \mathrm{b}}$, Davy Vancampfort ${ }^{\mathrm{c}, \mathrm{d}}$, Minna Mänty ${ }^{\mathrm{e}}$, Anna Svärd ${ }^{\mathrm{e}}$, Ossi Rahkonen ${ }^{\mathrm{e}}$, \\ Jouni Lahti ${ }^{\mathrm{e}, *}$ \\ a Physiotherapy Department, South London and Maudsley NHS Foundation Trust, Denmark Hill, London SE5 8AZ, United Kingdom \\ ${ }^{\mathrm{b}}$ Health Service and Population Research Department, Institute of Psychiatry, Psychology and Neuroscience, King's College London, De Crespigny Park, \\ London Box SE5 8AF, United Kingdom \\ ${ }^{c}$ KU Leuven - University of Leuven, Department of Rehabilitation Sciences, Leuven, Belgium \\ ${ }^{\mathrm{a}}$ KU Leuven - University of Leuven, University Psychiatric Center KU Leuven, Leuven-Kortenberg, Belgium \\ e Department of Public Health, University of Helsinki, P.O. Box 20, FIN-00014 Helsinki, Finland
}

\section{A R T I C L E I N F O}

\section{Keywords:}

Exercise

Physical inactivity

Mental health

Psychotropic medication

\begin{abstract}
A B S T R A C T
This study aimed to examine the bidirectional relationship between psychotropic medication use and changes in leisure-time physical activity (LTPA) among a population cohort study. Phase 1 data were collected by mail surveys in 2000-2002 among 40-60-year-old employees of the City of Helsinki, Finland, and phase 2 follow up survey was conducted in 2007. Based on self-report, the respondents were classified as inactive and active ( $\geq 14.75$ MET-hours/week) at the phases 1 and 2. Hazard ratios (HR) were calculated for subsequent (2007-10) psychotropic medication purchasing according to changes in physical activity (phases 1-2). Odds ratios (OR) for physical inactivity at phase 2 were calculated according to the amount of psychotropic medication between phases 1-2. Overall, 5361 respondents were included (mean age 50 years, 80\% women). Compared with the persistently active, the persistently inactive, those decreasing and adopting LTPA had an increased risk for psychotropic medication. Only the persistently inactive remained at increased risk for psychotropic medication use, following the adjustment for prior psychotropic medication use. Compared with those having no medication, the risk for physical inactivity increased as the psychotropic medication increased. Our data suggest that physical activity has an important role in maintaining wellbeing and reducing psychotropic medication usage.
\end{abstract}

\section{Introduction}

Physical activity has a range of benefits for health and well-being (Penedo and Dahn, 2005). Conversely, physical inactivity is attributed as the fourth leading cause of preventable mortality in the world, largely due to the increased cardiovascular risk profile (Kohl et al., 2012). Recently, interest has begun regarding the beneficial influence of physical activity on promoting good mental health. For instance, Mammen and Faulkner (2013) found in a systematic review that physical activity has a protective effect from future depression. The evidence base for physical activity and good mental health is increasing, with more and more interest developing to see if physical activity can prevent the onset of poor mental health outcomes. Moreover, in those with a pre-existing mental illness, exercise (a structured form of physical activity) has been demonstrated to improve depressive symptoms (Bridle et al., 2012; Rosenbaum et al., 2014; Carter et al., 2015; Schuch et al., 2016) and symptoms of schizophrenia including cognition (Firth et al., 2015, 2016).

While promoting physical activity and exercise are gaining credibility, pharmacotherapy remains the cornerstone for the multidisciplinary treatment of many people with mental health problems. In the past decade, the use of psychotropic medication has substantially increased, partly owing to the regulatory broadening of the indications for several psychotropic medications (Mojtabai and Olfson, 2010; Wu et al., 2013). Psychotropic medication is typically effective in alleviating mental health symptoms but also often has various side effects. In particular antipsychotics and to a lesser extent antidepressants and mood stabilizers, are associated with an increased risk for several

\footnotetext{
* Corresponding author.

E-mail address: jouni.mm.lahti@helsinki.fi (J. Lahti).
} 
chronic physical diseases, obesity, diabetes and cardio-metabolic diseases (Correll et al., 2015; Vancampfort et al., 2015a, 2015b). Higher dosages, polypharmacy, and treatment of vulnerable (e.g., old or young) individuals are associated with greater absolute (elderly) and relative (youth) risk. To what degree medication-specific and patientspecific risk factors interact, and how adverse outcomes can be minimized, allowing patients to derive maximum benefits from these psychotropic medications, requires adequate clinical attention and further research (De Hert et al., 2011). For example, since it is known that physical inactivity is an important risk factor for a wide range of chronic diseases and premature mortality (Kodama et al., 2009; Lahti et al., 2014), research is required to investigate whether psychotropic medication is a risk factor for lower physical activity and therefore future increased risk of cardiovascular disease outcomes. Surprisingly, no longitudinal, population cohort studies have considered whether higher levels of physical activity are associated with lower psychotropic medication use and if psychotropic medication is associated with less physical activity in the future. Understanding this relationship may have potential importance for mental health promotion, in addition to help identify if those in receipt of psychotropic medication are at risk of declining physical activity and therefore more at risk of cardiometabolic diseases.

Given the aforementioned, we set out to explore the bidirectional relationship between (a) changes in leisure-time physical activity and subsequent psychotropic medication use, and (b) psychotropic medication use and subsequent physical inactivity using data from the Helsinki Health Study (Lahelma et al., 2013).

\section{Methods}

\subsection{Study population}

The data from the current study were collected as part of the Helsinki Health Study. The Helsinki Health Study cohort was set up to enable longitudinal studies on the social and work related determinants of health and well-being, making use of self-reported as well as objective register data. The target population is the staff of the City of Helsinki, Finland (Lahelma et al., 2013). Follow-up survey data were collected from midlife employees of the City of Helsinki, Finland, at two time points: phase 1 (2000-2002) and phase 2 (2007) (Lahelma et al., 2013). Phase 1 data were collected by postal questionnaire surveys in 2000, 2001 and 2002. Questionnaires were mailed to all employees of the City of Helsinki who reached the age of 40, 45, 50, 55 and 60 during each survey year. The study has been approved by the ethics committees of the Department of Public Health, University of Helsinki and the health authorities of the City of Helsinki.

\subsection{Leisure-time physical activity}

The respondents were asked about their average weekly hours of leisure-time physical activity (commuting included) within the previous 12 months. Four intensity grades were given: walking, brisk walking, jogging, and running, or their equivalent activities. Approximate metabolic equivalents (MET-hours per week) were calculated for the volume of weekly leisure time physical activity. METhours per week were calculated by multiplying the time spent physically active by the estimated MET value of each four intensity grades (Kujala et al., 1998) and adding the four values together (Ainsworth et al., 2000). Respondents were classified as inactive according to the lowest tertile (under 14.75 MET-hours/week) or active when above this threshold (at least 14.75 MET-hours/week (Lahti et al., 2014). These two groups at the phases 1-2 yielded four groups describing persistency and changes over time in leisure-time physical activity.

\subsection{Psychotropic medication}

The purchases of prescribed psychotropic medication were classified according to the Anatomical Therapeutic Chemical (ATC) classification system (WHO Collaborating Centre for Drug Statistics Methodology, 2009). Any psychotropic medication included ATC codes N05 and N06 except medication for dementia N06D. The follow-up started on the day of returning the phase 1 questionnaire and continued for the entire year 2010. For examining the two separate research questions, psychotropic medication purchases were calculated separately for the period between phases 1-2 and the period after phase 2. For the first period (phases 1-2), the amount of psychotropic medication was calculated as defined daily doses (DDD's) i.e. the assumed medication dose per day used for its main indication. The DDD's were classified into four groups according to tertiles of medication use: 1 . No medication, 2. Low < 100 DDD's, 3. Medium $=100-700$ DDD's and 4. High > 700 DDD's. For the second period, the time to the first purchase was examined.

\subsection{Covariates}

Covariates included age, gender, socioeconomic position (SEP), smoking, binge drinking, body mass index (BMI) and physical functioning. The information on socioeconomic position (SEP) was taken from the phase 1 survey including four occupational social classes: managers (managerial and administrative work) and professionals (e.g. teachers and doctors), semi-professionals (e.g. nurses and foremen), routine non-manual (e.g. child minders and assistant maids) and manual workers (e.g. transport and cleaning work) (Lahelma et al., 2013). Smoking status change between phases 1 and 2 was classified into four groups: 1 . non-smokers, 2. became non-smokers, 3. became smokers and 4. smokers. Similar procedure was applied for binge drinking ( $\geq 6$ portions of alcohol more than once a month) (Paljärvi et al., 2009), being overweight (BMI $\geq 25 \mathrm{~kg} / \mathrm{m}^{2}$ ) (Svärd et al., 2016) and lowered physical functioning (under the maximum score of 100) measured by the physical functioning subscale of the Short-Form (SF36) health questionnaire (Ware, 2000).

\subsection{Statistical methods}

For estimating the effect of changes in physical activity (phases 12) on the risk of subsequent psychotropic medication use we used Cox regression analysis to calculate hazard ratios (HR) and their $95 \%$ confidence intervals $(95 \% \mathrm{CI})$ for first psychotropic medication purchase during the follow-up period 2007-2010. The persistently active group was used as the reference group. In model 1 age and gender were adjusted for. In model 2 covariates in model 1 and prior psychotropic medication (phases 1-2) were adjusted. In model 3 covariates in model 1 and physical functioning were adjusted. In model 4 covariates in model 2 and physical functioning, socioeconomic position, smoking, binge drinking and body mass index were adjusted. The proportional hazards assumption was confirmed using Schoenfeld residuals (Schoenfeld, 1982).

For estimating the effect of psychotropic medication use (phases 12 ) on the risk for physical inactivity (phase 2) we calculated odds ratios (OR) and their 95\% CI's for physical inactivity according to the amount of psychotropic medication purchases. Psychotropic medication purchase groups were compared to those without medication purchases. In model 1 age and gender were adjusted for. In model 2 covariates in model 1 and physical functioning were adjusted for. In model 3 covariates in model 1 and physical inactivity (phase 1) were adjusted. In model 4 covariates in model 1 and socioeconomic position, smoking, binge drinking and body mass index were adjusted for. SPSS 23 statistical package was used. 


\section{Results}

\subsection{Study population}

The target population consisted of 13346 employees. The response rates were $67 \%(n=8960)$ for phase 1 survey and $83 \%(n=7332)$ for the phase 2 survey. The questionnaire survey data were linked with the national register on prescribed, reimbursed psychotropic medication purchases obtained from the Social Insurance Institution of Finland (74\% of the phase 1 respondents gave informed written consent for the linkages). According to our non-response analyses, there were only minor differences between the survey respondents and non-respondents, although younger men and manual workers were slightly underrepresented among the respondents (Lahelma et al., 2013; Laaksonen et al., 2008). Not consenting to the data linkage showed even smaller differences than the survey non-response (Lahelma et al., 2013; Laaksonen et al., 2008). There were missing data in some of the study variables $(\mathrm{n}=214)$. The analyses included 5361 ( $80 \%$ women) respondents.

Among the 5361 participants (mean age 50 years) approximately $16 \%$ were persistently inactive from phase 1 to phase 2 and $53 \%$ were persistently active (Table 1 ). Approximately $16 \%$ moved from inactive
Table 2

Hazard ratios (95\% CI) and proportions (\%) for any psychotropic medication purchase after phase 2 by leisure-time physical activity change groups.

\begin{tabular}{|c|c|c|c|c|c|c|}
\hline \multicolumn{2}{|c|}{$\begin{array}{l}\text { Leisure time physical } \\
\text { activity }\end{array}$} & \multirow{2}{*}{$\begin{array}{l}\text { Psychotropic } \\
\text { medication } \\
\%\end{array}$} & \multirow[t]{2}{*}{ Model 1} & \multirow[t]{2}{*}{ Model 2} & \multirow[t]{2}{*}{ Model 3} & \multirow[t]{2}{*}{ Model 4} \\
\hline Phase 1 & Phase 2 & & & & & \\
\hline Inactive & Inactive & 32 & $\begin{array}{l}1.61 \\
(1.40- \\
1.85)\end{array}$ & $\begin{array}{l}1.37 \\
(1.19- \\
1.58)\end{array}$ & $\begin{array}{l}1.39 \\
(1.20- \\
1.60)\end{array}$ & $\begin{array}{l}1.37 \\
(1.18- \\
1.58)\end{array}$ \\
\hline Active & Inactive & 29 & $\begin{array}{l}1.39 \\
(1.19- \\
1.62)\end{array}$ & $\begin{array}{l}1.14 \\
(0.98- \\
1.34)\end{array}$ & $\begin{array}{l}1.24 \\
(1.06- \\
1.45)\end{array}$ & $\begin{array}{l}1.15 \\
(0.98- \\
1.35)\end{array}$ \\
\hline Inactive & Active & 25 & $\begin{array}{l}1.19 \\
(1.02- \\
1.39)\end{array}$ & $\begin{array}{l}1.13 \\
(0.97- \\
1.32)\end{array}$ & $\begin{array}{l}1.11 \\
(0.95- \\
1.30)\end{array}$ & $\begin{array}{l}1.13 \\
(0.97- \\
1.32)\end{array}$ \\
\hline Active & Active & 21 & 1.00 & 1.00 & 1.00 & 1.00 \\
\hline
\end{tabular}

Model 1 adjusted for age and gender.

Model 2 Model 1+ psychotropic medication phases 1-2.

Model 3 Model 1+ physical functioning.

Model 4 Model 2+ physical functioning, socioeconomic position, binge drinking, smoking, BMI.

Table 1

Description of study variables by leisure time physical activity change groups.

\begin{tabular}{|c|c|c|c|c|c|c|}
\hline Leisure-time physical activity & $\begin{array}{l}\text { Phase } 1 \\
\text { Phase } 2\end{array}$ & $\begin{array}{l}\text { Inactive } \\
\text { Inactive }\end{array}$ & $\begin{array}{l}\text { Active } \\
\text { Inactive }\end{array}$ & $\begin{array}{l}\text { Inactive } \\
\text { Active }\end{array}$ & $\begin{array}{l}\text { Active } \\
\text { Active }\end{array}$ & All \\
\hline N (\%) & & $911(17)$ & $728(14)$ & $864(16)$ & $2858(53)$ & 5361 \\
\hline Women (\%) & & 80 & 81 & 82 & 79 & 80 \\
\hline Age (mean) & & 51 & 49 & 50 & 49 & 50 \\
\hline \multicolumn{7}{|l|}{ Socioeconomic position (\%) } \\
\hline Manual workers & & 17 & 16 & 11 & 12 & 13 \\
\hline Routine non-manuals & & 35 & 38 & 33 & 33 & 34 \\
\hline Semi-professionals & & 18 & 19 & 21 & 21 & 20 \\
\hline Managers/professionals & & 31 & 27 & 35 & 34 & 33 \\
\hline \multicolumn{7}{|l|}{ Smoking (\%) } \\
\hline Smokers & & 21 & 21 & 15 & 13 & 16 \\
\hline Became smokers & & 2 & 1 & 1 & 2 & 2 \\
\hline Became non-smokers & & 7 & 7 & 7 & 5 & 6 \\
\hline Non-smokers & & 69 & 71 & 77 & 81 & 77 \\
\hline \multicolumn{7}{|l|}{ Binge drinking (\%) } \\
\hline Binge drinker ${ }^{\text {a }}$ & & 19 & 19 & 15 & 14 & 16 \\
\hline Became binge drinker & & 6 & 9 & 6 & 7 & 7 \\
\hline Became non-binge drinker & & 7 & 6 & 5 & 6 & 6 \\
\hline Non-binge drinker & & 68 & 67 & 74 & 73 & 71 \\
\hline \multicolumn{7}{|l|}{ Body mass index (\%) } \\
\hline Overweight $^{\mathrm{b}}$ & & 61 & 51 & 47 & 36 & 44 \\
\hline Became overweight & & 9 & 13 & 10 & 10 & 10 \\
\hline Became normal weight & & 5 & 3 & 5 & 4 & 4 \\
\hline Normal weight & & 26 & 33 & 39 & 50 & 42 \\
\hline \multicolumn{7}{|c|}{ Psychotropic medication Phases 1-2 (\%) } \\
\hline High $(>700 \mathrm{DDD})^{\mathrm{c}}$ & & 13 & 11 & 8 & 7 & 9 \\
\hline Medium (100-700 DDD) & & 11 & 11 & 11 & 8 & 9 \\
\hline Low ( < $100 \mathrm{DDD})$ & & 11 & 8 & 10 & 10 & 10 \\
\hline No medication & & 66 & 67 & 72 & 75 & 72 \\
\hline \multicolumn{7}{|l|}{ Physical functioning (\%) } \\
\hline Sub-optimal functioning & & 72 & 62 & 56 & 42 & 52 \\
\hline Became sub-optimal & & 11 & 15 & 16 & 17 & 16 \\
\hline Became optimal & & 6 & 6 & 11 & 10 & 9 \\
\hline Optimal functioning & & 11 & 15 & 17 & 31 & 23 \\
\hline
\end{tabular}

a $\geq 6$ portions of alcohol more than once a month.

b $\geq 25 \mathrm{~kg} / \mathrm{m}^{2}$.

${ }^{c}$ Defined Daily Dose. 
to active and $14 \%$ from active to inactive. In comparison, we calculated the proportions among those who did not consent to the register linkage ( $\mathrm{n}=1533$ ) which found only minor non-significant differences; persistent inactivity showed slightly more common (20\%) and persistent activity less common (50\%) than among the consenters. Among the study participants, those persistently active and those who became active tended to come less often from lower SEP groups (Table 1). In addition, they tended to be less often smokers and binge drinkers. There was also a tendency showing that those persistently active had less often overweight. Approximately 28\% of the respondents had psychotropic medication between phases 1-2 and the persistently active tended to have less often high psychotropic medication use and more often no medication.

\subsection{The effect of changes in physical activity on the risk of psychotropic medication use}

During the 2.3 years follow-up after phase 2, 25\% of the respondents received psychotropic medication, ranging from $21 \%$ among the persistently active to $32 \%$ among the persistently inactive (Table 2). Testing for interactions showed that the associations were similar for women and men ( $\mathrm{p}=0.9)$. Compared with the persistently active, those persistently inactive $(\mathrm{HR}=1.61,95 \% \mathrm{CI}=1.40-1.85)$, those decreasing $(\mathrm{HR}=1.39,95 \% \mathrm{CI}=1.19-1.62)$ and those adopting $(\mathrm{HR}=1.19,95 \%$ $\mathrm{CI}=1.02-1.39)$ physical activity had increased risk for the initiation of psychotropic medication in the age and gender adjusted model. Only the persistently inactive $(\mathrm{HR}=1.37,95 \% \mathrm{CI}=1.19-1.58)$ remained at increased risk for psychotropic medication use, when adjustment was made for prior psychotropic medication (Model 2). Similarly, adjusting for physical functioning attenuated the associations, whereas, additive adjustment for confounders had no effect.

\subsection{The effect of psychotropic medication use on the risk for physical inactivity}

Compared with those having no medication, the prevalence of physical inactivity at phase 2 increased in a dose-response manner as the amount of psychotropic medication use increased, ranging from $28 \%$ among those with no medication to $41 \%$ among those in the highest third ( $>700$ DDD's) of medication use (Table 3). Testing for interactions showed that the associations were similar for women and men ( $\mathrm{p}=0.2)$. In the age and gender adjusted model, compared to those without medication, those in the highest third of psychotropic medication purchases, had the highest risk for subsequent inactivity $(\mathrm{OR}=1.72,95 \% \mathrm{CI}=1.41-2.10)$. Those in the middle $(\mathrm{OR}=1.42,95 \%$ $\mathrm{CI}=1.16-1.72)$ and those in the lowest third $(\mathrm{OR}=1.24,95 \% \mathrm{CI}=1.02-$ 1.50) had also significantly increased risk for inactivity. Adjusting for physical functioning attenuated the associations and only the highest medication group remained at increased risk for physical inactivity $(\mathrm{OR}=1.45,95 \% \mathrm{CI}=1.18-1.77)$. Whereas adjusting for inactivity at phase 1 and other confounders had only slight attenuating effects.

\section{Discussion}

To the best of our knowledge the current study is the first to explore the longitudinal bidirectional relation between psychotropic medication use and changes in leisure-time physical activity. Our data show that persistently inactive people had an increased risk for the initiation of psychotropic medication compared with persistently active persons. Conversely, compared to those not in receipt of medication, the risk for subsequent physical inactivity increased in a dose-response manner as the amount of psychotropic medication increased. In summary, our results suggest a longitudinal inverse relationship between physical activity and mental health (expressed as psychotropic medication use). Therefore, the potential for physical activity to maintain and promote positive mental health and apparently reduce the need for psychotropic medication is important.

A number of studies have previously reported that decreases in physical activity levels over time increases the risk of developing depression (Camacho et al., 1991; Carroll et al., 2010), and vice versa (Gudmundsson et al., 2015). Moreover increasing levels of physical activity can reduce the risk of subsequent depression (Ball et al., 2009; Brown et al., 2005), and even maintaining some physical activity is associated with a lower risk of depression compared to those who remain totally inactive (Wise et al., 2006). Given the importance of maintaining good mental health and viewing psychotropic medication as a last resort to treat a mental disorders, our data suggest that maintaining physical activity levels may have a protective effect from subsequent psychotropic medication use. This is encouraging, particularly given the multiple side effects associated with psychotropic medication (Correll et al., 2015). Overall, the findings from our study suggest that increasing and maintaining physical activity over time should be encouraged in order to reduce the risk of developing poor mental health and being prescribed psychotropic medication. An alternative explanation of our data might be that the physical (in) activity is actually a proxy for mental health symptoms. For instance, it could be hypothesised that higher level of mental health symptoms require psychotropic medication and may therefore be related to lower levels of inactivity. Clearly, future longitudinal research is required to disentangle the relationships we observed and should attempt to ascertain the impact of mental health symptom severity.

Different mechanisms for the protective role of physical activity on psychotropic medication use can be hypothesised. On a neurobiological front, a number of acute changes occur during and following bouts of physical activity, and several long-term adaptations are related to regular physical activity. For instance, physical activity has been found to normalize reduced levels of brain-derived neurotrophic factor and therefore has neuro-protective or even neurotrophic effects (Szuhany et al., 2015). Animal studies have found physical activity-induced changes in the levels of different neurotransmitters such as dopamine (Clark et al., 2015), serotonin (Otsuka et al., 2016), glutamate (Real et al., 2010), and acetylcholine (Uchida et al., 2006), which relate to mood and beneficial effects on stress reactivity (e.g., the hypothalamuspituitary-adrenal axis). Potential psychosocial mechanisms include

Table 3

Odds ratios (95\% CI) and proportions (\%) for physical inactivity (phase 2) by any psychotropic medication (phases 1-2).

\begin{tabular}{|c|c|c|c|c|c|}
\hline $\begin{array}{l}\text { Psychotropic medication } \\
\text { Phases } 1-2\end{array}$ & $\begin{array}{l}\text { Inactive phase } 2 \\
(\%)\end{array}$ & Model 1 & Model 2 & Model 3 & Model 4 \\
\hline High $>700$ DDD & 41 & $1.72(1.41-2.10)$ & $1.45(1.18-1.77)$ & $1.65(1.33-2.03)$ & $1.53(1.25-1.87)$ \\
\hline Medium 100-700 DDD & 36 & $1.42(1.16-1.72)$ & $1.20(0.98-1.46)$ & $1.32(1.07-1.63)$ & $1.33(1.09-1.63)$ \\
\hline Low $<100$ DDD & 33 & $1.24(1.02-1.50)$ & $1.09(0.90-1.33)$ & $1.23(1.00-1.51)$ & $1.23(1.01-1.50)$ \\
\hline No & 28 & 1.00 & 1.00 & 1.00 & 1.00 \\
\hline
\end{tabular}

Model 1 adjusted for age and gender.

Model 2 Model 1+ physical functioning.

Model 3 Model 1+ physical inactivity at phase 1 .

Model 4 Model 1+ socioeconomic position, binge drinking, smoking, BMI. 
social reinforcement, experience of mastery in dealing with mental health problems, shift of external to more internal locus of control, improved coping strategies, or physical activity as distraction (Daley, 2002; Fox, 1999).

Conversely, our data suggest that psychotropic medication use (particularly among those with the highest DDD), is associated with future inactivity. Given the fact that psychotropic medication increases the risk of weight-gain and chronic physical diseases (Correll et al., 2015) and that physical activity may have a protective role in preventing such unwanted consequences (Rosenbaum et al., 2014), there is a need to develop appropriate future interventions to increase physical activity in this population. Previous research in people with recognised mental illnesses, such as depression (Stubbs et al., 2016) and schizophrenia (Vancampfort et al., 2015a, 2015b), have demonstrated that lower drop outs from physical activity are associated with supervision by qualified professional groups (e.g. physical therapists and/or exercise physiologists). Therefore, in those with particularly high psychotropic medication doses, interventions delivered by specialists may be required. Given the large numbers of people in receipt of psychotropic medication and the increased associated morbidity, investment in resources to increase physical activity in daily life for people receiving psychotropic medication may offer excellent value, both economically and from a mental and physical health perspective.

Whilst our results are novel and of interest, it is important that future prospective population cohort studies are conducted to confirm our findings. Future prospective cohort studies should if possible consider people across a spectrum of socioeconomic positions, both genders and attempt to disentangle the bidirectional relationship between different psychotropic agents. The latter will be particularly helpful to clinicians and those who prescribe medication. Moreover, future research should attempt to consider the impact of sedentary behaviour and capture this together with physical activity using appropriate objective methods such as accelerometers. Finally, future research should consider if physical activity prescription can prevent the need for psychotropic medication within a large pragmatic randomised control trial. Only under such circumstances will it be possible to address the question of causality in the associations we observed.

\subsection{Strength and limitations}

The current study has a number of strengths. We utilised a large cohort including both women and men exploring bidirectional associations between changes in leisure-time physical activity participation and psychotropic medication use. Next to this, we were able to control for a wide range of important covariates including age, gender, socioeconomic position, smoking, binge drinking, BMI and physical functioning. However, unmeasured and residual confounding is possible. The present findings need, however, be interpreted with caution as well because of some limitations of our data. Firstly, the participants were middle-aged public sector employees and $80 \%$ of them were women corresponding to the gender distribution of the target population and the municipal sector in Finland. Whilst the results are overrepresented by females, the associations we observed in our study were similar among women and men. Hence our data are not representative for the entire population, in particular for the most vulnerable groups for instance those being unemployed. Another limitation was the reliance on self-reported recall physical activity that lack validation, however, no single physical activity questionnaire has proven superior (van Poppel et al., 2010). Thirdly, non-response and attrition may be a problem in longitudinal cohort studies. In our study, the phase 1 response rate (67\%) was acceptable and good for the phase 2 (83\%). In addition, there was further attrition due to consenting to the register linkage. According to our non-response analyses e.g. the non-respondents were somewhat younger and from lower occupational classes and had slightly more long sickness absences than the responders, however, the differences were small and thus the results are unlikely to be markedly biased (Lahelma et al., 2013; Laaksonen et al., 2008). In addition, we showed that those consenting and not consenting to the register linkage had similar patterns of leisure-time physical activity between phases $1-2$, although physical inactivity was somewhat more common among the non-consenters. Due to attrition and the fact that all participants were initially employed the participants are a selected group i.e. healthier and physically more active than the general population and thus the results are probably conservative showing weaker associations than for general population (Li and Sung, 1999).

The medication data came from national health register. They are likely to be accurate since the information is originally collected for administrative purposes and used as the basis for monetary reimbursements. However, the purchases of prescribed psychotropic medication may not be considered as a direct measure of mental health problems. Whilst psychotropic medication is primarily utilised to treat common mental disorders, the use of certain classifications, such as antidepressants, is increasing for other conditions such as pain and sleep problems. In addition, there is comorbidity between common mental disorders such as anxiety and depression (Scott et al., 2007) and antidepressants are also prescribed for anxiety disorders (Sihvo et al., 2006) and we do not know the specific mental disorders that these medications were prescribed for. Our previous analyses have, however, shown similar associations between leisure-time physical activity and use of antidepressants and sedatives (Lahti et al., 2013). Thus we chose to use any psychotropic medication in our analyses examining the bidirectional associations in a longitudinal setting.

\section{Conclusions}

We examined bidirectional relationship between physical activity and psychotropic medication and found that physical activity is associated with a reduced need for psychotropic medication after adjusting for pertinent confounders. Moreover, psychotropic medication use, particularly in high doses, is associated with less physical activity. Given these findings, our data suggest that physical activity has an important role in maintaining wellbeing and reducing the need for psychotropic medication.

\section{Funding}

The study was supported by the Academy of Finland (grants 1129225, 1257362 and 1294514), the Ministry of Education and Culture (grant 6303383), the Finnish Work Environment Fund (grant 112231), the Research Foundation Flanders (FWO-Vlaanderen).

\section{Conflict of interest statement}

The authors declare that there are no conflicts of interest.

\section{Acknowledgements}

We thank the City of Helsinki and all the members of the Helsinki Health Study group for their contribution.

\section{References}

Ainsworth, B.E., Haskell, W.L., Whitt, M.C., Irwin, M.L., Swartz, A.M., Strath, S.J., O'Brien, W.L., Bassett, D.R., Jr, Schmitz, K.H., Emplaincourt, P.O., Jacobs, D.R., Jr, Leon, A.S., 2000. Compendium of physical activities: an update of activity codes and MET intensities. Med. Sci. Sports Exerc. 32, S498-S504.

Ball, K., Burton, N.W., Brown, W.J., 2009. A prospective study of overweight, physical activity, and depressive symptoms in young women. Obesity (Silver Spring) 17, 66-71.

Bridle, C., Spanjers, K., Patel, S., Atherton, N.M., Lamb, S.E., 2012. Effect of exercise on depression severity in older people: systematic review and meta-analysis of randomised controlled trials. Br. J. Psychiatry 201 (3), 180-185.

Brown, W.J., Ford, J.H., Burton, N.W., Marshall, A.L., Dobson, A.J., 2005. Prospective study of physical activity and depressive symptoms in middle-aged women. Am. J. 
Prev. Med. 29, 265-272.

Camacho, T.C., Roberts, R.E., Lazarus, N.B., Kaplan, G.A., Cohen, R.D., 1991. Physical activity and depression: evidence from the Alameda County study. Am. J. Epidemiol. 134, 220-231.

Carroll, D.D., Blanck, H.M., Serdula, M.K., Brown, D.R., 2010. Obesity, physical activity, and depressive symptoms in a cohort of adults aged 51 to 61. J. Aging Health 22, 384-398.

Carter, T., Guo, B., Turner, D., Morres, I., Khalil, E., Brighton, E., Callaghan, P., 2015 Preferred intensity exercise for adolescents receiving treatment for depression: a pragmatic randomised controlled trial. BMC Psychiatry 15, 247.

Clark, P.J., Amat, J., McConnell, S.O., Ghasem, P.R., Greenwood, B.N., Maier, S.F., Fleshner, M., 2015. Running reduces uncontrollable stress-evoked serotonin and potentiates stress-evoked dopamine concentrations in the rat dorsal striatum. PLoS One 10, e0141898.

Correll, C.U., Detraux, J., De Lepeleire, J., De Hert, M., 2015. Effects of antipsychotics, antidepressants and mood stabilizers on risk for physical diseases in people with schizophrenia, depression and bipolar disorder. World Psychiatry 14, 119-136.

Daley, A.J., 2002. Exercise therapy and mental health in clinical populations: is exercise therapy a worthwhile intervention? Adv. Psych. Treat. 8, 262-270.

De Hert, M., Correll, C.U., Bobes, J., Cetkovich-Bakmas, M., Cohen, D., Asai, I., Detraux, J., Gautam, S., Moller, H.J., Ndetei, D.M., Newcomer, J.W., Uwakwe, R., Leucht, S., 2011. Physical illness in patients with severe mental disorders. I. Prevalence, impact of medications and disparities in health care. World Psychiatry 10, 52-77.

Firth, J., Cotter, J., Elliott, R., French, P., Yung, A.R., 2015. A systematic review and meta-analysis of exercise interventions in schizophrenia patients. Psychol. Med. 45, 1343-1361.

Firth, J., Stubbs, B., Rosenbaum, S., Vancampfort, D., Malchow, B., Schuch, F., Elliott, R., Nuechterlein, K.H., Yung, A.R., 2016. Aerobic exercise improves cognitive functioning in people with Schizophrenia: a systematic review and meta-analysis. Schizophr. Bull.. http://dx.doi.org/10.1093/schbul/sbw115.

Fox, K.R., 1999. The influence of physical activity on mental well-being. Public Health Nutr. 2, 411-418.

Gudmundsson, P., Lindwall, M., Gustafson, D.R., Ostling, S., Hallstrom, T., Waern, M., Skoog, I., 2015. Longitudinal associations between physical activity and depression scores in Swedish women followed 32 years. Acta Psychiatr. Scand. 132, 451-458.

Kodama, S., Saito, K., Tanaka, S., Maki, M., Yachi, Y., Asumi, M., Sugawara, A., Totsuka, K., Shimano, H., Ohashi, Y., Yamada, N., Sone, H., 2009. Cardiorespiratory fitness as a quantitative predictor of all-cause mortality and cardiovascular events in healthy men and women: a meta-analysis. JAMA 301, 2024-2035.

Kohl, H.W., 3rd, Craig, C.L., Lambert, E.V., Inoue, S., Alkandari, J.R., Leetongin, G., Kahlmeier, S., Lancet Physical Activity Series Working Group, 2012. The pandemic of physical inactivity: global action for public health. Lancet 380, 294-305.

Kujala, U.M., Kaprio, J., Sarna, S., Koskenvuo, M., 1998. Relationship of leisure-time physical activity and mortality: the Finnish twin cohort. JAMA 279, 440-444.

Laaksonen, M., Aittomäki, A., Lallukka, T., Rahkonen, O., Saastamoinen, P., Silventoinen, K., Lahelma, E., 2008. Register-based study among employees showed small nonparticipation bias in health surveys and check-ups. J. Clin. Epidemiol. 61, 900-906.

Lahelma, E., Aittomaki, A., Laaksonen, M., Lallukka, T., Martikainen, P., Piha, K., Rahkonen, O., Saastamoinen, P., 2013. Cohort profile: the Helsinki health study. Int. J. Epidemiol. 42, 722-730.

Lahti, J., Holstila, A., Lahelma, E., Rahkonen, O., 2014. Leisure-time physical activity and all-cause mortality. PLoS One 9, e101548.

Lahti, J., Lallukka, T., Lahelma, E., Rahkonen, O., 2013. Leisure-time physical activity and psychotropic medication: A prospective cohort study. Prev. Med. 57, 173-177.

Li, C.Y., Sung, F.C., 1999. A review of the healthy worker effect in occupational epidemiology. Occup. Med. (Lond). 49, 225-229.

Mammen, G., Faulkner, G., 2013. Physical activity and the prevention of depression: a systematic review of prospective studies. Am. J. Prev. Med. 45, 649-657.

Mojtabai, R., Olfson, M., 2010. National trends in psychotropic medication polypharmacy in office-based psychiatry. Arch. Gen. Psychiatry 67, 26-36.
Otsuka, T., Nishii, A., Amemiya, S., Kubota, N., Nishijima, T., Kita, I., 2016. Effects of acute treadmill running at different intensities on activities of serotonin and corticotropin-releasing factor neurons, and anxiety- and depressive-like behaviors in rats. Behav. Brain Res. 298, 44-51.

Paljärvi, T., Koskenvuo, M., Poikolainen, K., Kauhanen, J., Sillanmäki, L., Mäkela, P., 2009. Binge drinking and depressive symptoms: a 5-year population-based cohort study. Addiction 104, 1168-1178.

Penedo, F.J., Dahn, J.R., 2005. Exercise and well-being: a review of mental and physical health benefits associated with physical activity. Curr. Opin. Psychiatry 18, 189-193.

Real, C.C., Ferreira, A.F., Hernandes, M.S., Britto, L.R., Pires, R.S., 2010. Exerciseinduced plasticity of AMPA-type glutamate receptor subunits in the rat brain. Brain Res. 1363, 63-71.

Rosenbaum, S., Tiedemann, A., Sherrington, C., Curtis, J., Ward, P.B., 2014. Physical activity interventions for people with mental illness: a systematic review and metaanalysis. J. Clin. Psychiatry 75, 964-974.

Schoenfeld, D., 1982. Partial residuals for the proportional hazards regression model Biometrica 9, 239-241.

Schuch, F.B., Vancampfort, D., Richards, J., Rosenbaum, S., Ward, P.B., Stubbs, B. 2016. Exercise as a treatment for depression: A meta-analysis adjusting for publication bias. J. Psychiatr. Res. 77, 42-51.

Scott, K.M., Bruffaerts, R., Tsang, A., Ormel, J., Alonso, J., Angermeyer, M.C., Benjet, C., Bromet, E., de Girolamo, G., de Graaf, R., Gasquet, I., Gureje, O., Haro, J.M., He, Y., Kessler, R.C., Levinson, D., Mneimneh, Z.N., Oakley Browne, M.A., Posada-Villa, J., Stein, D.J., Takeshima, T., Von Korff, M., 2007. Depression-anxiety relationships with chronic physical conditions: results from the World Mental Health surveys. J. Affect. Disord. 103, 113-120.

Sihvo, S., Hämäläinen, J., Kiviruusu, O., Pirkola, S., Isometsä, E., 2006. Treatment of anxiety disorders in the Finnish general population. J. Affect. Disord. 96, 31-38.

Stubbs, B., Vancampfort, D., Rosenbaum, S., Ward, P.B., Richards, J., Soundy, A., Veronese, N., Solmi, M., Schuch, F.B., 2016. Dropout from exercise randomized controlled trials among people with depression: a meta-analysis and meta regression. J. Affect. Disord. 190, 457-466.

Szuhany, K.L., Bugatti, M., Otto, M.W., 2015. A meta-analytic review of the effects of exercise on brain-derived neurotrophic factor. J. Psychiatr. Res. 60, 56-64.

Svärd, A., Lahti, J., Rahkonen, O., Lahelma, E., Lallukka, T., 2016. Obesity and psychotropic medication: a prospective register linkage study among midlife women and men. BMC Psychiatry 16, 185.

Uchida, S., Suzuki, A., Kagitani, F., Hotta, H., 2006. Responses of acetylcholine release and regional blood flow in the hippocampus during walking in aged rats. J. Physiol. Sci. 56, 253-257.

van Poppel, M.N., Chinapaw, M.J., Mokkink, L.B., van Mechelen, W., Terwee, C.B., 2010 Physical activity questionnaires for adults: a systematic review of measurement properties. Sports Med. 40, 565-600.

Vancampfort, D., Rosenbaum, S., Schuch, F.B., Ward, P.B., Probst, M., Stubbs, B., 2015a. Prevalence and predictors of treatment dropout from physical activity interventions in schizophrenia: a meta-analysis. Gen. Hosp. Psychiatry 39, 15-23.

Vancampfort, D., Stubbs, B., Mitchell, A.J., De Hert, M., Wampers, M., Ward, P.B., Rosenbaum, S., Correll, C.U., 2015b. Risk of metabolic syndrome and its components in people with schizophrenia and related psychotic disorders, bipolar disorder and major depressive disorder: a systematic review and meta-analysis. World Psychiatry 14, 339-347.

Ware, J.E., 2000. SF-36 health survey update. Spine 25, 3130-3139.

WHO Collaborating Centre for Drug Statistics Methodology, 2009. Guidelines for ATC Classification and DDD Assignment 2010. WHO Collaborating Centre for Drug Statistics, Oslo.

Wise, L.A., Adams-Campbell, L.L., Palmer, J.R., Rosenberg, L., 2006. Leisure time physical activity in relation to depressive symptoms in the Black Women's Health Study. Ann. Behav. Med. 32, 68-76.

Wu, C.H., Wang, C.C., Katz, A.J., Farley, J., 2013. National trends of psychotropic medication use among patients diagnosed with anxiety disorders: results from medical expenditure panel survey 2004-2009. J. Anxiety Disord. 27, 163-170. 